\title{
Correction
}

\section{Correction to: Relevance of Indian Summer Monsoon and its Tropical Indo-Pacific Climate Drivers for the Kharif Crop Production}

\author{
Hemadri Bhusan Amat ${ }^{1}$ and Karumuri AshoK ${ }^{1}$
}

Correction to: Pure Appl Geophys

https://doi.org/10.1007/s00024-017$1758-9$

In the original version of this article the name of one of the authors was written incorrect. The correct name is: Hemadri Bhusan Amat $^{1}$ and Karumuri Ashok $^{1}$

In the acknowledgements section the name of the Institution was written incorrect. And an additional thank you note was added. The correct Acknowledgment is as follows:
We acknowledge Charan Teja Tejavath and Reshma M. R, CEOAS, University of Hyderabad, for their assistance while dealing with various visualization tools. Also, we acknowledge our reviewers for their valuable comments and kind suggestions. Figures in the manuscript have been created using the COLA/GrADS software and ArcGIS.

We are really thankful to UGC for providing the $\mathrm{PhD}$ fellowship during the work period.

The original article has been corrected. 